\section{Notícies i novetats de l'Institut Botànic de Barcelona}

Collectanea Botanica (Barcelona)

vol. 29 (2010): 111-114

ISSN: 0010-0730

doi: 10.3989/collectbot.2010.v29.012

\title{
Notícies i novetats de l'Institut Botànic de Barcelona
}

\author{
A. SUSANNA \\ Institut Botànic de Barcelona (CSIC-ICUB), Psg. del Migdia s/n., 08038 Barcelona, Spain \\ E-mail: asusanna@ibb.csic.es
}

\section{Novetats a la biblioteca}

La biblioteca de l'Institut Botànic gaudeix de la presència d'una bibliotecària titular incorporada aquest any 2010, la senyora Karina Barros. La nova bibliotecària és funcionària del Ministeri de Cultura i prové del Museu d'Activitats Subaquàtiques de Cartagena. Aquesta desitjada incorporació posa fi a una provisionalitat de més de 16 anys, que és el temps transcorregut des de la jubilació de la bibliotecària precedent la senyora Teresa Formentí. Durant tots aquests anys, que inclouen fites com el trasllat al nou edifici o la incorporació del fons a la Xarxa de Biblioteques del CSIC, la biblioteca ha continuat donant servei gràcies a la dedicació generosa de la seva auxiliar Isidora Manso, i a un seguit de bibliotecaris contractats amb càrrec als programes de contractació de tècnics del CSIC: Sandra Valentí, Aurora Toboso, Yuri López, Ana María García, a més d'una curta interinitat dels bibliotecaris Eider Landajo i Abraham Ramírez, als quals l'Institut Botànic agraeix la seva voluntat i esforç.

\section{Una nova donació}

La biblioteca de l'Institut s'ha enriquit considerablement en l'àmbit de la bibliografia paisatgística amb la incorporació del llegat de la malauradament desapareguda paisatgista barcelonina Bet Figueras (1957-2010). L'arquitecta Bet Figueras és autora de l'original projecte paisatgístic del nou Jardí Botànic de Barcelona, basat en la interpretació dels diversos Mediterranis del món, que és una de les seves senyals d'identitat. La colllecció de llibres de jardineria i paisatge compta amb 1100 volums.

\section{La biblioteca Salvador en línia}

E1 2009, la Presidència del CSIC i el Ministeri de Cultura van signar un conveni de col-laboració específic amb una finalitat: donar accés al CSIC a les subvencions del Ministeri. Un dels primers resultats ha estat l'atorgament d'una subvenció destinada a la digitalització de tot el fons Salvador, constituït per prop d'un miler de llibres i nombrosos documents. Aquest any començarà la primera fase de l'escaneig dels volums de la col·lecció, tasca que es durà a terme a les mateixes instal-lacions de 1'Institut Botànic.

\section{Novetats a l'Herbari}

L'octubre del 2009 es va incorporar com a funcionària interina de l'ICUB i nova conservadora de l'herbari la doctora Neus Ibàñez, substituint el doctor Àngel Romo, que ha passat al CSIC com a investigador.

L'abril del 2010 també ha entrat com a tècnic superior de l'herbari i funcionària interina de l'ICUB la senyora Neus Nualart, que s'encarrega de les bases de dades i de la informatització de l'herbari. 


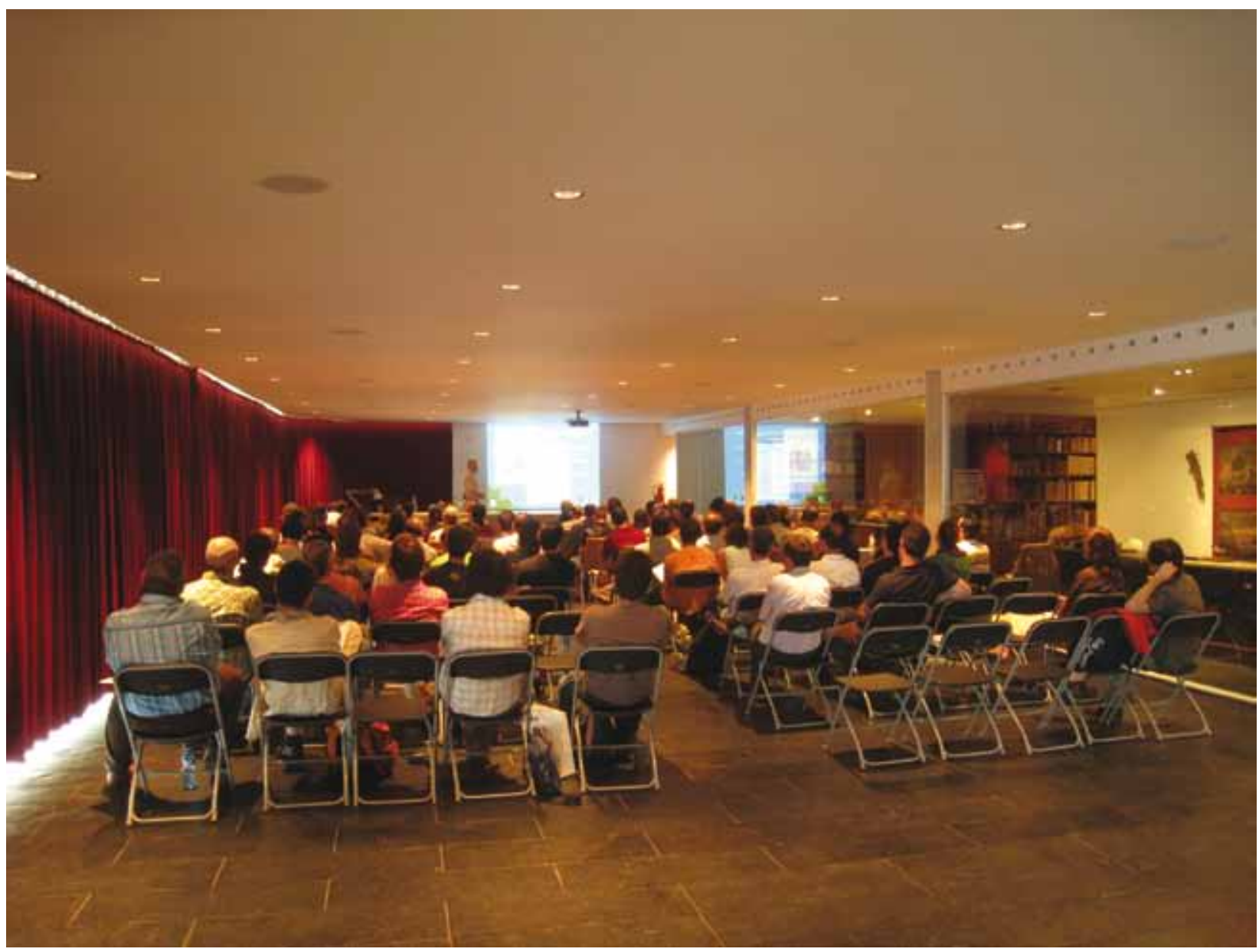

Aspecte de la Sala Salvador de 1'Institut Botànic durant les sessions científiques de les II Jornades [Fotografia: Jordi López-Pujol].

Continuant amb la bona dinàmica del departament, el març d'aquest any es va incorporar la senyora Noemí Montes, amb un contracte temporal de l'ICUB aconseguit gràcies al suport de la Fundació Mellon. Aquesta associació sense ànim de lucre dóna ajudes per digitalitzar plecs tipus de diferents herbaris. Enguany ha subvencionat el projecte LAPI (Latin American Plants Initiative) per informatitzar i escanejar els plecs tipus d'Amèrica Llatina que es conserven a l'herbari de l'Institut. La senyora Montes durà a terme aquesta tasca fins a finals de novembre d'aquest any. Posteriorment, aquestes imatges es podran consultar a la pagina web http://plants.jstor.org. Actualment ja s'han digitalitzat 300 tipus i esperem arribar als 1000 plecs $i$ altres documents.

Finalment, el mes de juliol ha començat a treballar Diana Muñiz, que s'encarrega d'informatitzar 1'herbari general fins a finals d'any. Aquest contracte s'ha aconseguit gràcies a les ajudes per informatitzar plecs i exportar-los al GBIF (Global Biodiversity Information Facility, http://www. gbif.es/) del Ministerio de Ciencia e Inovación i del CSIC.

\section{Jornades Catalanes de Conservació de Flora}

Els dies 7, 8 i 9 de juny es va celebrar la segona edició de les Jornades Catalanes de Conservació de Flora a l'Institut Botànic, organitzades pel mateix institut, el Jardí Botànic de Barcelona i el Departament de Medi Ambient i Habitatge de la Generalitat de Catalunya. Les Jornades, que van comptar amb la presència de prop de 140 experts $i$ professionals vinguts d'arreu dels Països Catalans, es van estructurar en cinc sessions temàtiques 


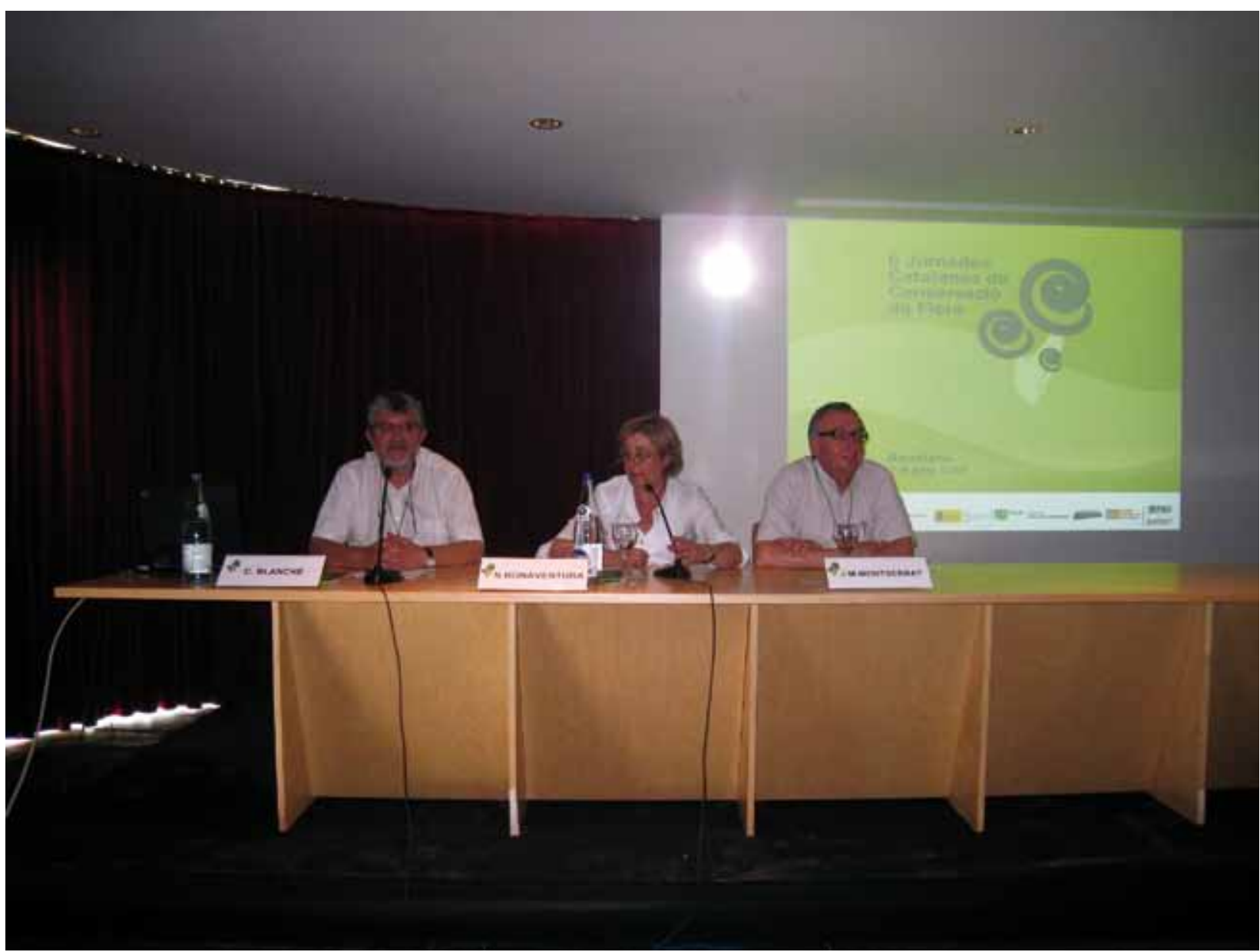

Sessió de clausura de les II Jornades, a càrrec de Cèsar Blanché, Núria Bonaventura i Josep Maria Montserrat [Fotografia: Jordi López-Pujol].

abastant tots els camps de la conservació de la flora (avaluació i diagnòstic de l'estat de conservació de la flora, conservació ex situ, recerca en biologia de la conservació, planificació i estratègies de conservació, i experiències de conservació i gestió de la flora).

Al llarg de les jornades es van presentar un total de 66 comunicacions, repartides entre 8 ponències convidades, 28 comunicacions orals i 30 comunicacions en forma de pòster. D'entre les ponències més destacades, cal mencionar la presentació del llargament esperat i necessari "Llibre Vermell" de la flora vascular de Catalunya, i l'exposició del Euphorbia Planetary Biodiversity Inventory a càrrec de Paul E. Berry, investigador principal del projecte. Els membres de l'Institut Botànic van contribuir activament a les diferents sessions científiques, presentant un total de sis comunicacions (dues orals i quatre en pòster).

Les jornades van finalitzar amb l'important compromís d'impulsar l'Estratègia Catalana de Conservació de Flora (ECCF) i també de celebrar una tercera edició de les mateixes l'any 2012. A la pàgina web de les II Jornades (http://www.jornadesflora.cat/) pot descarregar-se tant el llibre de resums com moltes de les comunicacions presentades en format pdf.

\section{Eugeni Sierra i Ràfols}

El febrer de 2010 es va inaugurar a l'Institut Botànic una exposició sobre la vida i l'obra d'un il-lustrador botànic genial, el doctor honoris causa Eugeni Sierra i Ràfols (1919-1999), 


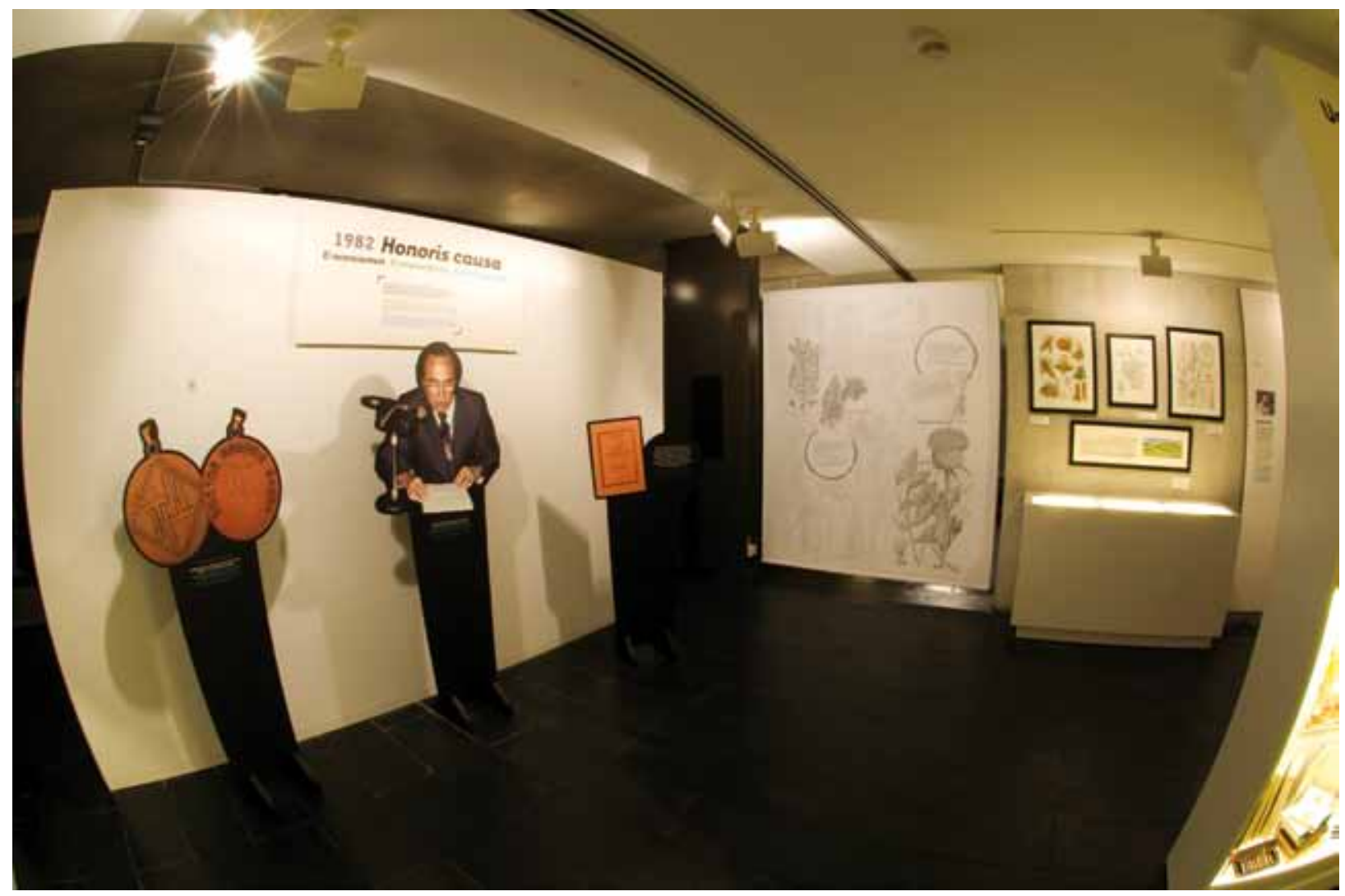

Exposició “Descobrir Eugeni Sierra. Les passes d'un il·lustrador internacional” [Fotografia: Carme Puche].

estretament vinculat al nostre institut (va ser director del jardí botànic als anys 70). L'exposició, comissariada per Carles Puche i Carme Puche, romandrà oberta fins al febrer de 2011 i és una oportunitat per veure reunida per primera vegada una representació amplíssima d'una obra ingent i malauradament molt dispersa. L'exposició inclou també una acurada reconstrucció d'una vida difícil i plena d'experiències, molt lligada a la història de la postguerra espanyola. La mostra ha comptat amb una estreta col-laboració de tota la botànica catalana i amb un suport generós, documental i d'obra original, per part del Real Jardín Botánico de Madrid (CSIC), editor d'una de les obres més importants a la qual va contribuir Sierra amb les seves il·lustracions: Flora iberica. 